\title{
SUJETO Y MUNDO. \\ PREMISAS ONTOLÓGICAS DEL CONCEPTO KANTIANO DE AUTONOMÍA DE LA RAZÓN
}

\author{
FRANCISCO BLANCO BROTONS \\ CSIC. Instituto de Filosofía (Madrid)
}

\begin{abstract}
RESUMEN: En este artículo nos preguntamos por la ontología del ser racional finito presupuesta en los planteamientos normativos kantianos y por la dinámica histórica de «realización» a la que da lugar. En ningún caso se trata con ello de atribuir a Kant una derivación del deber ser a partir del ser. Nos preguntamos por el ser del deber-ser. Si aceptamos denominar "ontología fundamental» a aquella indagación universal del sentido del ser que arraiga en la problematización del ser del sujeto, mi hipótesis es que en el factum de la conciencia del deber-ser, como ratio cognoscendi de la libertad, alienta una ontología fundamental más allá del idealismo trascendental. En el discurso de Kant la apertura de este problema tiene lugar con la Crítica del Juicio y hace emerger como pieza clave de este nivel de inteligibilidad el concepto de mundo.
\end{abstract}

PALABRAS CLAVE: Kant; libertad; autonomía; hetenonomía; razón práctica; sujeto práctico; mundo; sentido común; sociabilidad; naturaleza humana; educación; comunidad; Estado; cultura.

\section{Subject and World. \\ Ontological premises of Kantian concept of autonomy of Reason}

ABSTRACT: On this paper we ask ourselves about the ontology of the finite rational being in Kan't normative theory and about the historic dynamics of «realization» that it sets in motion. With this we don't pretend to attribute to Kant a derivation of what ought to be from what is. If we agree to call "fundamental ontology» to that universal inquiry about the sense of the being that takes root in the problematization of the subject' being, my hypothesis is that the factum of the concience of the ought-to-be, like ratio cognoscendi of the freedom, heartens a fundamental ontology beyond the trascendental idealism. The opening of this problem in Kant's discourse takes place with the Critique of Judgement and reveals the concept of world like a key piece in this level of intelligibility.

KEY WORDS: Kant; freedom; autonomy; heteronomy; practical reason; practical subject; world; common sense; sociability; human nature; education; community; state; culture.

\section{INTRODUCCIÓN}

La condición fundamental del ser humano en tanto que ser racional finito, problema que Kant intentó resolver con su Crítica del Juicio, es el siguiente: el ser humano es un ser que pertenece a un doble ámbito de ser, sensible e inteligible, sometido a dos legislaciones distintas, la de la naturaleza y la de la libertad, pero cuya vida se desenvuelve en un único territorio, el de la experiencia. No obstante, la ley moral nos impone el deber de realizar la naturaleza inteligible, de realizar la libertad y sus leyes en el mundo de los sentidos (respetando las leyes de este). Se nos impone el deber último de realizar el sumo bien en el mundo, de modo que la legalidad natural coincida con la posibilidad de los fines logrables por las leyes de la libertad, que no haya contradicción entre felicidad y virtud. Kant insiste en el gran abismo que se abre entre los fenómenos y lo suprasensible: las leyes de la naturaleza se mantienen plenamente separadas 
(deben mantenerse plenamente separadas) de las leyes prácticas de la libertad, y éstas no determinan nada sobre el conocimiento teórico de la naturaleza. Pero la posibilidad de la realización del sumo bien exige un modo de conectar estos dos ámbitos. ¿Cómo cerrar este abismo? ¿Cómo es este territorio de la experiencia en el que se desarrolla el juego entre nuestra naturaleza sensible e inteligible?

En el ámbito de las leyes de la libertad, lo único situado fuera de la naturaleza es el fundamento (inteligible) que determina la causalidad por el concepto de libertad, pero la voluntad determinada por este concepto de libertad es ya una de las varias causas naturales en el mundo. Esta es la razón por la que lo sensible no puede determinar lo suprasensible del sujeto, pero la determinación de lo sensible por lo suprasensible (a través de la voluntad determinada por este) sí es posible, pero esta determinación debe siempre operarse en el mundo según las leyes formales de la naturaleza. No puede haber obstáculo o fomento entre la naturaleza y la libertad, «sino entre la primera como fenómeno y las acciones de la última como fenómenos en el mundo de los sentidos, y aun la causalidad de la libertad (de la razón pura y práctica) lo es de una causa natural (del sujeto considerado como hombre y, por ende, como fenómeno) subordinada a aquélla, conteniendo lo inteligible, concebido como libertad, el fundamento de su determinación de un modo que, por otra parte, es inexplicable» ${ }^{1}$.

La acción autónoma, la realización de nuestra naturaleza racional en el mundo, es el fin último que debe existir, cuya condición de posibilidad es el hombre (como ser racional sensible) en el mundo. Todo ser racional sensible tendrá su mundo específico para aspirar a su realización, mundo que él mismo (en cuanto especie) habrá elaborado. El objeto de este texto será exponer las características y exigencias generales que este concepto de mundo introduce, en tanto que único ámbito en el que el ser humano puede avanzar hacia la autonomía. Pero en tanto que el hombre es el único ser racional sensible que conocemos, sólo podremos referirnos a su mundo.

En la Crítica del Juicio, Kant plantea un discurso sobre la esencia de la humanidad del hombre que se desarrolla en paralelo a la ontología del mundo. Éste no será un ámbito meramente contextual, externo o complementario al del hombre, sino que el despliegue de la ontología del mundo implica el despliegue de la ontología del hombre. Es un objetivo ulterior de este trabajo mostrar que no estamos aquí ante una nueva filosofía o una ruptura, sino que la tercera crítica cumple una posición central en la coherencia global del planteamiento kantiano de un sujeto práctico situado sobre el abismo de la libertad. Que la Crítica del Juicio ocupa esta posición central es una hipótesis fundamental que organiza mi lectura de la obra de Kant, en virtud de lo cual interpreto las obras de antropología pragmática, de filosofía política, del derecho o de la historia a través de este libro. Es decir, rechazo la idea de una «cuarta crítica» e interpreto que las obras normalmente incluidas en esta idea no son sino desarrollos del planteamiento de la tercera.

\footnotetext{
1 Kant, I., Crítica del Juicio. Buenos Aires, Losada, 2005. Nota p.40.
} 
Este artículo se divide en cuatro partes. En la primera se expondrán los rasgos fundamentales que estructuran ese ámbito ontológico en el que el ser racional finito debe y puede autorrealizarse. Ese ámbito, naturalmente, es el mundo. En las siguientes tres partes se caracterizan los tres espacios que se abren en este mundo para alcanzar la autonomía. En la primera de ellas, «La naturaleza humana en el mundo», se estudia la exigencia que se le impone al hombre, en tanto que ser racional finito, de desarrollar su propia naturaleza, pues esta no está fija de antemano y sin embargo en el desarrollo que el ser racional finito hace de sus disposiciones se encuentra la posibilidad de que alcance o no su fin. El siguiente apartado, «Educación», se centra en la idea de educación y en la importancia del principal fin de esta, forjarse un carácter. El último apartado, "La elaboración de la comunidad», atiende al papel de la sociedad, de la cultura, del Estado y de la comunidad ética en el progreso hacia la autorrealización del hombre. Pretendemos aquí comprender por qué la instauración del Estado y de la comunidad ética es condición necesaria para cualquier progreso hacia la autonomía, dando especial énfasis a la idea de reino de los fines.

\section{El CONCEPTO DE MUNDO}

Kant sitúa en la facultad de juzgar la posibilidad de enlazar las dos legislaciones a las que se somete el hombre, la del entendimiento (leyes de la naturaleza) y la de la razón (leyes de la libertad) a través de un concepto que aquella facultad presupone a priori: el concepto de una idoneidad de la naturaleza como mediador entre los conceptos naturales y el de la libertad, lo que posibilitaría que la naturaleza, de acuerdo con sus leyes, acogiese el fin último de la libertad. ¿Pero qué significa esta idoneidad? De acuerdo con Éric Weil $^{2}$, entre la ciega y mecánica legalidad natural y la naturaleza racional, ella nos abre ese espacio fenoménico intermedio que es propio del hombre, ese espacio en el que él desarrolla su existencia y puede aspirar a la realización; ella nos abre el mundo, el espacio de la posibilidad de nuestro fin último. El cosmos carece de orientación, la idoneidad sólo surge en tanto que el hombre actúa guiado por su razón práctica. Sólo la ley moral determina al ser racional como fin en sí, pero a la vez lo determina como último fin de una naturaleza fenoménica con sentido. Sólo por la moralidad damos un sentido a nuestra existencia, y a través de esto, damos sentido también al mundo. Se vincula, de este modo, naturaleza y libertad.

Tres hechos se dan a la inteligencia finita que es el hombre: la ciencia, en el ámbito fenoménico, conformado a priori por los conceptos del entendimiento; la ley moral, apertura hacia lo inteligible, posibilitada por la razón; y el sentido, que configura y llena el mundo, el espacio de la existencia y posible realización

2 WeIL, É., Problemas kantianos. Madrid, Escolar y Mayo, 2013. 
del hombre, donado a priori por el juicio. «Ahora el sentido es un hecho, los hechos tienen un sentido; ésta es la posición fundamental de la última Crítica» ${ }^{3}$. La idoneidad de la naturaleza, la adecuación de lo dado a un fin, se presenta al hombre, es hecho, es algo con lo que necesariamente se nos presenta el mundo pero que no pertenece propiamente a lo dado. No hay sentido objetivo, pero lo dado siempre se nos presenta con un sentido porque la facultad de juzgar no legisla sobre la materia de los sentidos sino tan sólo sobre ella misma. El sentido particular es fortuito, pero esto no significa que éste sea aleatorio o caprichoso. Todo lo contrario, el mundo es una totalidad estructurada, relacional, que se impone como marco previo para toda pregunta que nos planteemos. El mundo, de este modo, posee dos características: es el ámbito del sentido y es una totalidad relacional. Totalidad construida por el hombre a través de su facultad de juzgar, pero en ella, lo primero con lo que el hombre se encuentra es consigo mismo. Mundo es «un conjunto de seres distintos de mí, pero que se hallan en relación de comunidad conmigo» ${ }^{4}$. El mundo tiene una tercera característica fundamental, posee una constitutiva apertura a los otros hombres, el mundo es nuestra casa a costruir entre todos. El sentido con el que comprendemos las cosas y a nosotros mismos, los fines que nos planteamos... en todo esto está ya la mediación de los otros. El mundo es producto nuestro, pero a la vez es el marco del sentido del hombre, constituye «un sistema de actualidad que envuelve toda existencia real. Envuelve esta existencia a la vez porque es el concepto de su totalidad, y porque a partir de él ella desarrolla su realidad concreta [...] El mundo es la raíz de la existencia, la fuente que, al contenerla, al mismo tiempo la retiene y libera $»^{5}$.

Esta característica del mundo de ser un todo relacionado de sentido que se construye entre todos nosotros, nos conduce a la comunicación entre los hombres, condición necesaria para la construcción del mundo. Este marco que envuelve nuestra existencia se realiza, actualiza y mantiene en los intercambios y relaciones concretas que establecen los hombres particulares entre sí. No es un marco cuya verdad, aun siendo la raíz de nuestra existencia, resida en significaciones trascendentes, sino que se juega en cada instante y adquiere toda su verdad mundana en cada acto de comunicación entre hombres. El lenguaje y la red de intercambio que éste posibilita constituye el medio de afirmación del mundo. La comunicación implica la posibilidad de que el sentido, y por lo tanto el mundo, sean compartidos. Es el sentido común, que se define como un acuerdo de las facultades (imaginación, entendimiento y razón) entre sí, lo que constituye la condición subjetiva de toda comunicabilidad. En relación con el hecho del sentido, del que no podemos aspirar a encontrar una verdad objetiva sino sólo coincidencia subjetiva (porque el juicio no legisla sobre lo dado sino sólo sobre sí mismo), nuestra construcción del mundo nos lanza al

\footnotetext{
3 Ib., 57.

4 Kant, I., Antropología en sentido pragmático. Madrid, Alianza Editorial, 2010, 29.

5 Foucault, M., Introducción a la Antropología en sentido pragmático. Madrid, Siglo XXI, 2010, 91.
} 
interminable juego de una concordancia libre e indeterminada entre facultades (juego en el que la sensibilidad y la imaginación tendrán un importante papel), buscando las reglas fortuitas y exclusivamente subjetivas que rijan nuestros juicios reflexionantes (que no esquematizan bajo reglas o conceptos dados a priori). Este juego busca un sentido común para nuestras reglas, busca reglas compartidas para nuestros juicios, busca un mundo común de sentido compartido. Acuerdo que tenemos que construir, postular, experimentar y poner a prueba en cada uno de nuestros encuentros intersubjetivos. Acuerdo que tenemos que suponer igual para todos, aunque no tengamos evidencia objetiva de ello, para comprender la posibilidad de la comunicación. Y en última instancia, acuerdo y comunicación, que podemos y debemos extender cosmopolítamente entre todos los ciudadanos del mundo.

Para la realización de lo suprasensible en lo sensible, los postulados de la Razón (libertad, inmortalidad y existencia de Dios) no son las únicas condiciones, faltan las condiciones inmanentes del mundo que fundan la capacidad de éste para acoger lo suprasensible: la finalidad de la naturaleza, lo bello y lo sublime. A las creencias racionales hay que añadir la construcción del sentido que hacemos entre todos poniendo en juego nuestra imaginación. Esta también forma parte del sentido moral común. A la base de nuestra existencia en el mundo está la posibilidad de una concordancia libre y subjetiva de nuestras facultades. Esta concordancia es producida por nosotros en nuestros encuentros comunicativos, por lo que será transformable y variable tanto en el tiempo como en el espacio. Podemos denominar cultura a lo incluido en esta concordancia, variable entre los diferentes grupos de nuestra especie. La cultura será el medio a través del que avanzamos colectivamente hacia nuestro elevado fin, para lo cual debemos rechazar que las diferentes configuraciones culturales sean alguna entidad esencial limitada a sí misma, sino que se tratan de coincidencias transitorias entre grupos de individuos que nunca deben renunciar a la comunicación con otros. Para la realización de nuestro más elevado destino común nunca podemos renunciar a nuestra universabilidad: la humanidad es una y su posible destino universal también.

El hombre encuentra la raíz de su existencia en este mundo que le envuelve y que a la vez construye él mismo mediante sus intercambios comunicativos. El hombre pertenece a este mundo del que no puede salir, pero no así el imperativo moral, fuente última de su libertad y del sentido del mundo, no. Preparar la realización de la libertad en la naturaleza es el fin del juicio reflexionante y sus dos modalidades estética y teleológica. El mundo es el ámbito en el que se hace posible y real la humanidad de los hombres, el desarrollo de su potencial universal. En el ciudadano del mundo toma cuerpo un universal concreto, una posición particular en el espacio que se abre bajo el horizonte de la verdad universal del hombre, espacio en el que se despliega la relación entre la verdad del hombre y su libertad. La naturaleza ha creado a los hombres de modo que puedan comunicarse entre ellos y puedan crear entre todos un mundo donde realizar su fin supremo, que no es sino la organización de todos los seres racionales bajo la ley moral o la autonomía. 
En este mundo, en el que el hombre puede y debe realizar su fin supremo, lo primero con lo que este se encuentra es consigo mismo y con los otros como él. Consigo mismo como miembro de su especie, dotado de cierta naturaleza. Con los otros como formando parte de una comunidad organizada. El sentido de ambos aspectos lo debe él mismo construir, y de esta elaboración dependerá el progreso de la especie hacia su fin inteligible. Las vías hacia la autonomía en el mundo serán tres: la autoelaboración de su propia naturaleza, la educación de los individuos y la elaboración de la comunidad.

\section{LA NATURALEZA HUMANA EN EL MUNDO}

Si el auténtico fin del hombre fuese su felicidad, la Naturaleza habría estado muy desacertada al dotarle de la razón, pues una vida ajustada a un comportamiento instintivo habría alcanzado con exactitud mecánica ese fin, como ocurre con el resto de animales sobre la Tierra. «El hombre no debía ser dirigido por el instinto o sustentado e instruido por conocimientos innatos; antes bien, debía extraerlo todo de sí mismo» ${ }^{6}$. A la Naturaleza no le ha importado que el hombre sea feliz, sino que deba su estatuto y su dignidad sólo a sí mismo. Cualquier deleite, cualquier carácter de su voluntad, son enteramente obra suya. Sólo a él corresponde la responsabilidad de avanzar hacia su fin: el supremo bien en el mundo, fin que ningún individuo podrá cumplir, sino sólo su especie, como clase de seres racionales sensibles. Pero para alcanzar este fin, la Naturaleza le ha dotado de ciertas disposiciones naturales y además: «Todas las disposiciones naturales de una criatura están destinadas a desarrollarse alguna vez completamente y con arreglo a un fin ${ }^{7}$. Corresponde al hombre desarrollar estas disposiciones originarias, estudiarlas, darles sentido y usarlas como poderes para alcanzar su fin. Entre el hombre-animal y el hombre-racional se abre el espacio de la elaboración y utilización de nuestra naturaleza para alcanzar nuestro fin. Nuestro mundo es el espacio evolutivo del animal-racional, en el que paralelamente a la evolución que él mismo obra de sus disposiciones, podrá aspirar al desarrollo de la humanidad. Posiblemente nuestras disposiciones en un momento histórico particular sean más complejas, y nuestras capacidades más amplias, que en momentos históricos precedentes, pero la necesidad de seguir elaborándolas será tan urgente como en cualquier otro momento. El estudio y comprensión de nuestras disposiciones, fuerzas o posibilidades naturales, en tanto que ellas son lo que nosotros mismos hemos hecho de ellas, constituye el terreno de una antropología pragmática cuyo dominio será el universal concreto, nuestras posiciones concretas en el espacio abierto entre la animalidad instintiva y la libertad.

6 KANT, I., Idea para una historia universal en clave cosmopolita. Madrid, Gredos, 2010, 16.

7 Ib., 15. 
Esos conjuntos de fenómenos que habitualmente comprendemos como ya dados, inmóviles, naturalmente anudados y clausurados, tales como las razas, los cuerpos, el sexo, etc., así como habilidades particulares que generalmente creemos datos naturales como el pensar, nuestra inteligencia o astucia, etc., se nos revelan ahora como posibilidades de nuestra autoelaboración.

Una criatura racional particular experimenta por sí misma, gracias a la razón, «la capacidad de ampliar las reglas e intenciones del uso de todas sus fuerzas por encima del instinto natural, y no conoce límite alguno a sus proyectos» ${ }^{8}$. Esta libertad negativa que cada cual experimenta como ruptura instintiva y apertura a la libre e ilimitada imaginación, rompe nuestra animalidad, pero aún no nos pone en camino hacia nuestra humanidad. No conocemos límites a nuestros proyectos, pero si nos lanzamos a una ilimitada imaginación particular, sin reconocer modelos ni proyectos estables, siempre estaríamos en un punto inicial. Nuestro fin último, así como la elaboración de nuestra naturaleza, sólo se pueden desarrollar dentro de la especie, pues sólo esta es inmortal. Para desarrollar la antropogénesis, debemos trabajar por una imaginación común, vinculada y compartida, que pueda evolucionar junto con la especie y que no retorne a un momento inicial con la muerte de cada individuo. Esta imaginación vinculada a modelos y proyectos estables sólo podrá ser un producto social y cultural. En palabras de Villacañas: «la sociedad es el ámbito en el que se juega el proceso de la permanente antropogénesis histórica. El ethos animal queda superado aquí»" ${ }^{9}$ La base natural humana debe elaborarse de forma social, pero paradójicamente, el medio del que se sirve la sabia Naturaleza para fomentar el desarrollo de las disposiciones dentro de la sociedad, es el antagonismo social, la insociable sociabilidad. El hombre tiene una inclinación a socializarse, pues entiende que sólo en este estado se da la posibilidad de desarrollar sus disposiciones, pero también, fruto de su amor propio, tiene una propensión a separarse. Esta circunstancia despierta sus fuerzas y lo empuja a desarrollar sus posibilidades, hasta "finalmente, transformar un consenso social urgido patológicamente en un ámbito moral» ${ }^{10}$.

La primera consecuencia de la ruptura con la base instintiva, causada por el despertar de la razón en él, supuso que el hombre comenzase a fingir deseos con ayuda de la imaginación, sin contar con los impulsos naturales. En virtud de esto, "se fue tramando poco a poco todo un enjambre de inclinaciones superfluas [...] pero el éxito de este primer intento, es decir, el tomar conciencia de su razón como facultad que puede sobrepasar los límites donde se detienen todos los animales fue algo muy importante y decisivo para el modus vivendi del hombre ${ }^{11}$. La toma de conciencia de su elección libre le mostró su capacidad para elegir su propia manera de vivir, pero esta conciencia despierta de inmediato miedo y angustia, pues coloca al hombre ante un abismo en el

\footnotetext{
8 Ib., 16.

Villacañas Berlanga, J. L., Dificultades con la Ilustración. Madrid, Verbum, 2013, 70.

10 KANT, I., Idea para una historia universal en clave cosmopolita. Madrid, Gredos, 2010, 17.

11 Kant, I., Probable inicio de la historia humana. Madrid, Gredos, 2010, 116.
} 
que se abre una infinitud de nuevos deseos e inclinaciones. Se abre ante él un futuro que no está escrito de antemano, que tiene que proyectar él mismo, un futuro de deseos e inclinaciones que son obra suya. Pero la razón es también una disposición que debe elaborar. Lo mandado por el instinto no es un vicio, es extra-moral, sólo cuando la animalidad se mezcló con la razón, y siendo esta una disposición débil y no desarrollada, se originan males y vicios. "La historia de la Naturaleza comienza por el bien, pues es obra de Dios; la historia de la libertad comienza por el mal, pues es obra del hombre» ${ }^{12}$.

El conjunto de todas estas inclinaciones, que son obra nuestra, constituye el egoísmo. Este supone o el amor propio o la complacencia. El egoísmo nace en nosotros antes que la razón y que la ley moral y en caso de dejarnos guiar por él impide el desarrollo de nuestra moralidad y, por lo tanto, impediría alcanzar nuestro fin último. Recordemos que para Kant no toda forma de amor propio es rechazable.

Que el hombre pueda tener una representación de su yo lo realza infinitamente sobre los otros seres vivientes sobre la tierra y es necesario para su autorrealización. En la Crítica de la razón práctica Kant distinguía entre este amor propio (philautía) y un egoísmo rechazable (Eigendünkel) por pretender instaurarse como tirano legislador de todo mi yo. En la Antropología, situado en el nivel de lo que hemos hecho de nuestra naturaleza, Kant distingue tres clases de egoísmo ${ }^{13}$. Primero, el egoísta lógico, que cree innecesario contrastar su juicio con el de los demás. Pero según Kant, «no podemos prescindir de este medio para asegurarnos la verdad». En segundo lugar, el egoísta estético, al que le basta su propio gusto, y así, «se priva a sí mismo de progresar y mejorar, aislándose en su propio juicio». Finalmente, el egoísta moral, que reduce todos los fines a sí mismo, a su propia felicidad, despreciando la idea del deber. De este modo, "como cada hombre se hace un concepto distinto de lo que considera como felicidad, es justamente el egoísta quien llega a no tener piedra de toque del verdadero concepto del deber, la cual ha de ser un principio de validez universal». El egoísmo nos impide asegurarnos la verdad, progresar y mejorar, y llegar al verdadero concepto del deber. En la Crítica de la razón práctica, Kant insistía en el quebranto que la razón pura práctica causa a mi yo-egoísta, al someterlo a la ley moral. En la Antropología, Kant le opone el pluralismo, "esto es, aquel modo de pensar que consiste en no considerarse ni conducirse como encerrado en el propio yo el mundo entero, sino como un simple ciudadano del mundo».

El hombre, sin duda, debe preocuparse por su yo, pues es un fin en sí mismo. Pero para ello debe comprender que la vía no es encerrarse en su querido yo. La vía no es la del egoísmo, sino la del pluralismo. Cada uno de nosotros es fin en sí mismo en virtud de su capacidad de desplegar su personalidad, en tanto que seres racionales, y esto nos pone en pie de igualdad con los otros seres humanos.

12 Ib., 120.

13 Kant, I., Antropología en sentido pragmático. Madrid, Alianza Editorial, 2010, 27-29. 
Para aspirar a nuestra realización no simplemente debemos desarrollar nuestra razón considerada como mero instrumento para la satisfacción de las distintas inclinaciones (como mera inteligencia), no debemos considerar sólo la satisfacción de nuestros fines en tanto que meramente míos, subjetivos. Dado que nuestra naturaleza no es plenamente racional, nuestros fines no son necesariamente objetivos. No podemos encerrarnos en nuestro propio yo para pretender encontrar allí la objetividad, pues de este modo nunca podremos saber si lo que consideramos objetivo lo es realmente. Sólo mediante la piedra de toque que aporta el pluralismo podremos aspirar a acceder a una inteligencia racional, a elevarnos a fin en sí objetivo y universal. Sólo la comunidad y comunicación con el resto de los seres humanos nos permitirá aspirar a desarrollar nuestra naturaleza racional en el mundo, nuestro potencial universal.

\section{EdUCACIÓN}

El ser humano debe sacar de sí mismo, poco a poco, desarrollar por su propio esfuerzo, todas las disposiciones de la humanidad, desplegar su autonomía racional y su universalidad. El ser humano debe humanizarse, pero para lograrlo, una sola vía abre su porvenir: la educación. «Únicamente por la educación el hombre puede llegar a ser hombre» ${ }^{14}$. El hombre debe desarrollar las disposiciones para el bien que la naturaleza ha depositado en él, sacar el bien de sí mismo. Pero para poder alcanzar su destino, debe formarse una idea de qué pueda ser este, una idea de una perfección que no se encuentra en la experiencia, sino que es obra de la razón. El arte de la educación necesita ser razonado porque las disposiciones para la humanidad no se desarrollan por sí mismas. Esta idea de perfección debe pasar de generación en generación, abierta a un esforzado mejoramiento, paralelo al perfeccionamiento de la humanidad misma. «Antes no tenían los hombres ningún concepto de la perfección que la naturaleza humana puede alcanzar. Nosotros mismos no lo poseemos aún con pureza. Pero es asimismo cierto que, obrando aisladamente los hombres en la formación de sus alumnos, no podrán conseguir que éstos alcancen su destino. No son los individuos, sino la especie humana quien debe llegar aquí. La educación es un arte, cuya práctica ha de ser perfeccionada por muchas generaciones ${ }^{15}$. El hombre debe educarse a sí mismo. Imperfecto como es, debe aclararse a sí mismo la idea de su perfección, y como no puede ser educado sino por otros hombres también imperfectamente educados, su visión de hasta dónde llegan sus disposiciones naturales será siempre parcial.

El desarrollo de la razón en el mundo depende de la educación, pero esta a su vez depende del desarrollo de la razón. Por este motivo la educación es, junto con la instauración de un gobierno justo, el problema más grande del

14 Kant, I., Pedagogía. Madrid, Akal, 1991, 31.

15 Ib.,34. 
hombre. De aquí que la educación y el perfeccionamiento del ser humano, no podrán avanzar sino poco a poco. Labor conjunta de la especie humana. Aquí no hay sabios iluminados que hayan contemplado por sus solas fuerzas la verdad. La minoría de edad sólo la superará la especie, pero el esfuerzo debe realizarlo cada ser humano individualmente, participando en un proceso reflexivo, público y compartido.

Para desarrollar nuestras disposiciones para el bien objetivo de la educación, debemos recordar que no hay en nuestra naturaleza disposiciones para el mal, sino que «la única causa del mal es el no someter la Naturaleza a reglas. En los hombres solamente hay gérmenes para el bien ${ }^{16}$. Para desarrollar nuestras disposiciones al bien, hay que someter la Naturaleza a reglas, lo cual logra en una serie sucesiva de pasos. El primer paso es la disciplina, una educación meramente física de las facultades del espíritu. Los animales están ya ajustados a su destino por instinto. El hombre, por el contrario, necesita construirse él mismo el plan de su conducta. Pero como nace inculto debe recibir un plan ya construido por los demás. «La disciplina impide que el hombre, llevado por sus impulsos animales, se aparte de su destino, de la humanidad. Tiene que sujetarle, por ejemplo, para que no se encamine, salvaje y aturdido, a los peligros» ${ }^{17}$. La disciplina es la acción por la que se aleja al hombre de la barbarie, entendida esta como la independencia respecto de las leyes, y se le somete a las leyes de la humanidad. Esta es la parte de la educación que más tempranamente debe realizarse en su vida, pues el hombre tiene una fuerte inclinación hacia una salvaje libertad sin ley, y si no se le acostumbra desde el comienzo a someterse a los preceptos de la razón, no se le podrá ya orientar hacia su destino. El siguiente paso consiste en cultivarse, esto es, adquirir la habilidad para alcanzar los fines propuestos, habilidades culturales muy diversas en función de la infinita multitud de los fines. El tercer paso educativo será civilizarse, es decir, adquirir la prudencia necesaria para servirse pragmáticamente de otros hombres para alcanzar nuestros fines.

Cultivarse y civilizarse contribuyen sin duda a realizar nuestro destino, pero no suponen aún el surgimiento del bien. Este es sólo moral. El objetivo más elevado de la educación, al que todos los anteriores deben estar orientados, debe ser desarrollar la moralización. «El hombre no sólo debe ser hábil para todos los fines, sino que ha de tener también un criterio con arreglo al cual sólo escoja los buenos. Estos buenos fines son los que necesariamente aprueba cada uno y que al mismo tiempo pueden ser fines para todos» ${ }^{18}$. Educar para la moralización implica que todo debe orientarse a que el niño aprenda a pensar y a que obre por principios, es decir, que se forje un carácter. Debe aprender a cultivar la libertad por coacción: hay que acostumbrarle a sufrir una coacción en su libertad y al mismo tiempo guiarle para que haga buen uso de ella.

\footnotetext{
16 Ib.,36-37.

17 Ib., 30 .

18 Ib.,38-39.
} 
Se le educa para que comience a elevarse hacia lo objetivo, hacia los fines y principios válidos para todos, y para ello hay que enseñarle primero que el uso que haga de su libertad no debe ser un obstáculo para la libertad de los otros. La educación en la moral se refiere sólo al uso de la libertad, a obrar según las propias máximas y no por costumbres. Que el alumno no simplemente haga el bien, sino que lo haga porque es bueno.

La educación moral debe fundar un carácter, esto es, formar en el niño el modo de pensar que consiste en la facilidad para obrar por máximas que se ha prescrito inmutablemente por medio de su propia razón. Un carácter no trata de lo que la naturaleza hace del hombre, sino de lo que éste hace de sí mismo. «Todas las demás buenas y útiles cualidades del hombre tienen un precio, por el que pueden trocarse por otras de igual utilidad; [...] pero el carácter tiene un valor intrínseco y está por encima de todo precio» ${ }^{19}$. En educarse para adquirir un carácter (educarse en la moral) reside la posibilidad de darse a sí mismo un valor y dignificarse. No hay peligro de que este carácter se base en principios malos. La maldad de un hombre no puede ser propiedad de su carácter (lo que sólo es posible en seres diabólicos), pues la maldad sólo puede proceder del abandono de los principios, no de estos. De tal modo que, con seguridad, educar en el carácter, por imperfectos que sean los principios que eventualmente se puedan adoptar, aleja la maldad del hombre.

La educación sólo puede ser preparatoria para que acontezca la revolución del alma que supone forjarse un carácter: «La educación, los ejemplos y la enseñanza no pueden producir esta firmeza y perseverancia en los principios poco a poco, sino sólo como por medio de una explosión [...] el fundamento de un carácter es la absoluta unidad del principio interno de la conducta en la vida en general $»^{20}$. Para facilitar esta explosión, tan necesaria como posible para cualquiera, hay que enseñar a los niños el deber tanto para consigo mismo (la dignidad que todo hombre alberga en su interior, siendo su deber no desmentir esta dignidad de la humanidad en su persona) y el deber para con los demás (respeto al derecho de todo ser humano).

\section{LA ELABORACIÓN DE LA COMUNIDAD}

\subsection{El reino de los fines}

La moralidad es la única condición bajo la que un ser racional puede ser fin en sí mismo, de modo que su autorrealización sea su propio y legítimo fin. Ahora bien, el fin natural de todo hombre, en tanto que ser sensible, es su propia felicidad, pero simultáneamente, en tanto que ser racional (moral), los fines de cualquier otro sujeto que también es fin en sí mismo tienen que ser

19 Kant, I., Antropología en sentido pragmático. Madrid, Alianza Editorial, 2010, 230.

$20 \mathrm{Ib}, 233$. 
también mis fines. El hombre legítimamente se preocupa por su existencia, por satisfacer sus fines subjetivos, pero para la promoción de la humanidad, se precisa algo más: transformar nuestros fines meramente subjetivos en objetivos, de modo que puedan ser compartidos por todo otro ser racional y favorezcan la promoción de la humanidad en su conjunto. De esto se sigue la «suprema condición de la concordancia de la voluntad con la razón práctica universal, la idea de la voluntad de cualquier ser racional como una voluntad que legisla universalmente» ${ }^{21}$, la idea de una voluntad racional que se somete a la ley como autolegisladora. Kant llama a este axioma el principio de la autonomía de la voluntad, siendo inherente al mismo el concepto de un reino de los fines, una conjunción sistemática de seres racionales bajo leyes objetivas comunes autoimpuestas por cada ser racional que forma el reino. Tratándose de seres puramente racionales, todas las voluntades estarían naturalmente de acuerdo entre sí, los fines subjetivos de cada uno serían también objetivos en tanto que compatibles con toda otra voluntad racional.

Sin embargo, los seres humanos no somos este tipo de ser racional, pues somos simultáneamente seres sensibles; este reino de los fines no puede ser para nosotros más que un ideal. Para cumplir nuestro fin, el imperativo nos dice que tenemos que promover la razón de modo que podamos compatibilizar a los seres humanos como fines en sí subjetivos, lo cual permitiría que el hombre se elevase en fin en sí objetivo. Debemos aceptar la guía universal de la razón, desarrollar lo universal en nosotros, y trascender así el azar de nuestra animalidad. Contemplar nuestra existencia en el mundo desde la perspectiva del reino de los fines nos permitirá apreciarnos como fines en sí objetivos. Somos más que seres inteligentes (capaces de utilizar la razón como mero instrumento para la satisfacción de las inclinaciones). Somos seres racionales, y al perseguir nuestros fines subjetivos debemos plantearnos cómo a través de éstos promovemos los fines objetivos de todo ser racional. Promover la humanidad en nosotros es igual que promover la humanidad de los demás, y sólo se logra apostando por la objetividad y universalidad de la razón, y dado que el punto de vista racional no se logra simplemente por mera introspección, porque nuestra naturaleza no es puramente racional, debemos abrirnos al punto de vista de los otros si queremos construir el reino de los fines en la Tierra. Desarrollar nuestra moralidad, trabajar por el bien supremo en el mundo, fin último de nuestra existencia, será sólo posible si consciente y activamente nos esforzamos por realizar el reino de los fines en el mundo.

\subsection{La cultura}

El hombre como ser moral es el fin último de la naturaleza y nos aproximamos a nuestro fin último trabajando por el despliegue del reino de los fines en el

${ }_{21}$ Kant, I., Fundamentación para una metafísica de las costumbres. Madrid, Alianza ed., 2002, 119. 
mundo, por lo que podemos suponer que este despliegue es así mismo fin de la naturaleza. Podemos y debemos aquí, por lo tanto, «buscar qué puede hacer la naturaleza para prepararlo y qué puede hacer él mismo para ser fin final ${ }^{22}$. El hombre no es fin último de la naturaleza en tanto que ser inteligente capaz de satisfacer su deseo de felicidad, sino en tanto que ser moral, capaz de abstraer la materia sensible de sus fines de cara a la universalidad racional. Por lo tanto, de todos sus fines en la naturaleza, sólo queda la condición formal subjetiva, esto es, la aptitud para ponerse fines a sí mismo y usar la naturaleza como medio, en conformidad con la ley moral. ¿Y qué es realizable dentro de los parámetros del mundo a favor de esta condición formal subjetiva, es decir, a favor del despliegue del reino de los fines en el mundo? Algo que estructura y atraviesa el mundo de un extremo a otro: la cultura. «Lograr que un ser racional sea apto para cualesquiera fines (por consiguiente, en su libertad), se llama cultura; por lo tanto, sólo ella puede ser el último fin atribuido con causa a su naturaleza con respecto al género humano ${ }^{23}$, siendo los últimos pasos de la cultura, para que la naturaleza pueda alcanzar su designio final, la instauración de una sociedad civil (Estado) y de un todo cosmopolita. La naturaleza nos prepara para la realización del reino moral de los fines civilizándonos. Desde el momento de liberación instintiva, de entrada en una libertad salvaje, el fin último del destino moral de la especie humana será que la cultura, en su perfeccionamiento, se torne nuevamente naturaleza, pero esta vez, naturaleza racional.

La cultura es el desarrollo de nuestra habilidad para cumplir los fines que me planteo. Para lograr este desarrollo, que como vimos antes necesariamente se da en sociedad y mediado por el lenguaje, la naturaleza se sirve del antagonismo dentro de la sociedad, «en la medida en que ese antagonismo acaba por convertirse en la causa de un orden legal de aquellas disposiciones $»^{24}$. Se despiertan así las fuerzas del hombre que le hacen vencer su propensión a la pereza y le permiten desarrollar poco a poco todos sus talentos. Todas las ciencias, las artes, así como todo bello orden social son fruto de la insociable sociabilidad, que permiten acceder a una imaginación vinculada, a modelos, proyectos y fines estables y comunicables que nos sumergen en procesos concretos y más amplios que los meramente individuales, lo que nos permite apropiarnos de lo ya conquistado por otros y avanzar en un movimiento global y progresivo. La cultura nos sumerge en un movimiento colectivo sólo en el cual el progreso en el desarrollo de nuestras disposiciones, proyectos, fines, habilidades, etc., es posible.

\subsection{La comunidad civil jurídica}

La instauración del Estado, de una constitución civil, «es el grado supremo en el arte de acrecentar las buenas disposiciones que tiene la especie humana

22 Kant, I., Crítica del Juicio. Buenos Aires, Losada, 2005, 299.

$23 \mathrm{Ib}, 300$.

24 KANT, I., Idea para una historia universal en clave cosmopolita. Madrid, Gredos, 2010, 17. 
para llegar al fin último de su destino» ${ }^{25}$. Desde el ejercicio de nuestra libertad debemos conquistar nuestra dignidad moral siguiendo el imperativo categórico, debemos contemplar nuestra existencia según el modelo del reino de los fines y aspirar a elevar nuestros fines meramente subjetivos a fines objetivos. Para ello es necesaria la instauración de una sociedad civil que haga compatibles los fines que cada cual nos proponemos, con los fines de los demás, pero sin arrebatar a ninguno de los agentes morales su libertad para decidir por sí mismo su proyecto de vida bueno, pues sólo así podremos desarrollar la moralidad y conquistar nuestra dignidad. Sólo dentro de una sociedad civil en la que se reconozca a cada ser humano su estatuto de fin en sí mismo, y su derecho a seguir el camino que le parezca bueno, siempre que no obstaculice el mismo derecho de los demás, podremos avanzar hacia el principio de la autonomía de la voluntad y la instauración del reino de los fines en el mundo.

La creación y el mantenimiento del Estado es un deber racional porque sólo dentro de él es posible avanzar hacia nuestro fin último, pero su instauración histórica, sólo pudo realizarla el hombre urgido patológicamente por la naturaleza. «Una sociedad en la que la libertad bajo leyes externas se encuentre vinculada en el mayor grado posible con un poder irresistible, esto es, una constitución civil perfectamente justa, tiene que ser la tarea más alta de la naturaleza para con la especie humana. [...] La necesidad le obliga al hombre, tan proclive sin embargo a la libertad sin ataduras, a ingresar en ese estado de coerción y tal necesidad es en verdad la mayor de todas, a saber, la que se infligen mutuamente a sí mismos los hombres, cuyas inclinaciones hacen que no puedan coexistir durante mucho tiempo en salvaje libertad ${ }^{26}$. Esta tarea será la más difícil de las que tenga que resolver la especie humana, pues la inclinación egoísta del hombre le tienta a exceptuarse a sí mismo de la ley que como criatura racional desea para que se pongan límites a la libertad de todos. Por todo esto el hombre precisa de un señor que le obligue a obedecer esa ley, pero este señor, que debe ser justo, no puede sin embargo dejar de ser él mismo un ser humano.

Para aproximarnos a la solución de este problema, Kant nos propone el ideal de la constitución civil republicana según tres principios: «1..$^{\circ}$ de la libertad de los miembros de una sociedad (en cuanto hombres), 2. ${ }^{\circ}$ de la dependencia de todos respecto a una única legislación común (en cuanto súbditos) y 3 . $^{\circ}$ de conformidad con la ley de la igualdad de todos los súbditos (en cuanto ciudadanos). Y es la única constitución que se deriva de la idea del contrato originario y sobre la que debe fundarse toda la legislación jurídica de un pueblo» ${ }^{27}$. El republicanismo es la traducción del ideal del reino de los fines a un ideal jurídico y su objetivo es la transformación del mundo hacia un sistema de seres racionales autolegisladores bajo leyes universales y objetivas fruto de

25 Kant, I., Antropología en sentido pragmático. Madrid, Alianza Editorial, 2010, 273.

26 Kant, I., Idea para una historia universal en clave cosmopolita. Madrid, Gredos, 2010, 18-19.

27 Kant, I., La paz perpetua. Madrid, Tecnos, 2013, 17-18. 
una voluntad general racional que unifique a la humanidad entera. Ningún ser humano debe quedar fuera de esa voluntad general, pues mientras que esto ocurra, no se habrá alcanzado un sistema racional. Es además un sistema en el que esta voluntad general debe conformarse desde un diálogo público y libre. Republicanismo es un sistema cuyas instituciones deben servir para que los seres humanos se aclaren sobre sí mismos, sobre lo justo o lo bueno. Este ideal que Kant nos propone sirve también para valorar y modificar toda constitución jurídica realmente existente.

Para Kant, el Estado indudablemente arranca de los individuos, pues es instaurado como un medio para garantizar que cada sujeto pueda desarrollar su vida, proyectos y fines subjetivos, libre de la coacción de los demás, pero no lo relativiza hasta ser un mero servidor de intereses particulares, pues sólo puede cumplir su función a través del esfuerzo activo y sostenido por aproximarse a la objetividad racional. Kant nos presenta la libertad como el único derecho innato, que nos faculta para obligar a otros por el simple hecho de nacer como ser humano y con independencia de todo acto jurídico. «No hay sino un derecho innato. La libertad (la independencia con respecto al arbitrio constrictivo de otro), en la medida en que puede coexistir con la libertad de cualquier otro según una ley universal, es este derecho único, originario, que corresponde a todo hombre en virtud de su humanidad $»^{28}$. Es innato porque es una condición necesaria de nuestro ser moral. Y este derecho individual, en un reino de los fines que integre a otros seres racionales, sólo podrá desplegarse desde el principio de la autonomía y auto-legislación de cada voluntad. De aquí que la libertad externa, la que es objeto explícito del derecho, quede definida como «el derecho a no obedecer ninguna ley externa a la que no haya podido darle mi consentimiento ${ }^{29}$. Estas ideas llevan implícito el reconocimiento de una igualdad innata como «no ser obligado por otros sino a aquello a lo que también recíprocamente podemos obligarles $»^{30}$, de modo que cada integrante del reino de los fines en el mundo sea a la vez sujeto y objeto de una voluntad común racional y objetiva. El despliegue de la libertad e igualdad en el mundo sólo será posible en el marco de un Estado y sólo podrá progresar asumiendo el ideal de constitución republicana, y modificando según él, y en la medida que cada momento histórico lo permita, las constituciones realmente existentes.

Pero el ideal del reino de los fines no es realizable en el interior de algún Estado particular frente a otros, pues su objeto único e indivisible es la humanidad. El progreso hacia el fin del hombre tiene necesariamente dimensión cosmopolita. El primer paso en esta dirección tendría que ser la regulación del antagonismo interestatal. Toda libertad salvaje impide el progreso, y si bien el antagonismo es beneficioso, debe ser limitado y regulado. Entre estados también se puede dar una libertad salvaje, de modo que «los pueblos — como Estados— pueden considerarse

28 Kant, I., La Metafísica de las Costumbres. Madrid, Tecnos, 2008, 48-49.

29 Kant, I., La paz, perpetua. Madrid, Tecnos, 2013, 18.

30 Kant, I., La Metafísica de las Costumbres. Madrid, Tecnos, 2008, 49. 
como individuos que se hacen daño unos a otros en su estado de naturaleza —es decir, en un estado sin leyes externas - sólo por su mera coexistencia y cada uno de ellos puede y debe exigir al otro, en aras de su seguridad, que entre con él en una constitución similar a la constitución del Estado» ${ }^{31}$.

El último paso sería establecer un derecho cosmopolita que reconozca a cada ser humano como ciudadano del mundo, un derecho de hospitalidad y de visita, «derecho a ofrecerse como compañía que corresponde a todos los hombres, en virtud del derecho a poseer en común la superficie de la tierra, sobre la que los hombres no pueden dispersarse hasta el infinito, por ser una superficie esférica, sino que al final tienen que tolerarse los unos junto a los otros» ${ }^{32}$. Sólo a través de un derecho cosmopolita que posibilite la comunicación de toda la humanidad entre sí, más allá de Estados y pueblos particulares, podremos construir poco a poco, entre todos, un sentido común que constituya nuestro propio orden humano, mediante el que elaboremos nuestra humanidad. Sólo multiplicando nuestros encuentros recíprocos en tanto que seres humanos, podremos progresar y dar sentido, en paz, entre todos, a nuestra existencia humana universal.

\subsection{La comunidad civil ética}

Ante todo lo dicho hasta ahora, no debemos perder de vista cuál es el fin del hombre: el desarrollo de la moral en el mundo. Parece apropiado recordar aquí la observación que hizo Cassirer a Heidegger en su famoso debate de Davos: «el mundo humano y, por ende, la esencia del hombre, tienen sin duda su punto de partida, su fundamento original, en el mundo de la acción menesterosa, en relación con "lo que se halla al alcance de la mano", o sea, en la existencia cotidiana, pero no alcanzan su meta sino en el reino autónomo y libre del espíritu, único ámbito en donde pueden desplegar su auténtico sentido» ${ }^{33}$. Todo lo que la naturaleza pueda hacer hacia este fin no serán más que preparativos, pues la moral está fuera de la naturaleza y depende exclusivamente del hombre en tanto que sujeto moral. La existencia del hombre sólo puede desarrollarse en el mundo, pero su destino racional trasciende a este. La relación fundamental para la realización del hombre se establece entre la ley moral y el individuo, no con la sociedad, los pueblos, Estados... Estos son sólo medios con respecto a la moral. Es decir, el instrumento-Estado es necesario para el desarrollo de la disposición al bien al elevar los fines meramente subjetivos hacia la objetividad, pero «con esto se da un gran paso hacia la moralidad - aunque no sea todavía un paso moral $»^{34}$. La realización del fin último no pasa por lo que la naturaleza puede hacer, sino por lo que nosotros, seres sensibles y racionales, podemos y debemos hacer con la naturaleza y con nosotros mismos.

31 Kant, I., La paz perpetua. Madrid, Tecnos, 2013, 25-26.

32 Ib.,33.

33 Aramayo, R. R.(ed.), Cassirer y su Neo-Ilustración. Madrid, Plaza y Valdés, 2009, 71-71.

34 Kant, I., La paz perpetua. Madrid, Tecnos, 2013, 64. 
La moralidad debe realizarse en el mundo, pero para esto el Estado sigue siendo insuficiente. Los individuos deben construir una comunidad no sólo jurídica, sino ética, en la que los sujetos se esfuercen por cumplir con la ley moral, y no sólo por ser subjetivamente felices, en la que todos los sujetos se aclaren mutuamente sobre sus deberes y fines objetivos, con la clara conciencia de estar construyendo una humanidad común. La comunicación cosmopolita, que construye un sentido común global, va claramente en esta dirección. Lo difícil de este proceso de aclaración conjunta es que sólo puede ser impulsado desde cada conciencia moral personal, pero realizado en público y para la humanidad. Debe sintetizar lo individual y lo colectivo. Los seres humanos no somos puros seres racionales que libre y espontáneamente coincidamos en el respeto a la ley moral, pero contra toda la impureza y fragilidad moral que observamos, siempre conservaremos un fondo moral que nos autoriza a «presentar la especie humana no como una especie mala, sino como una especie de seres racionales que tiende a elevarse del mal al bien en un constante progreso entre obstáculos» ${ }^{35}$. La moralización del mundo es un proceso continuo e infinito (progresivo o regresivo, depende de nosotros) de aproximación hacia el ideal del reino de los fines. En este proceso avanza la humanidad en su conjunto, ningún sujeto alcanzará en solitario su destino moral. La revolución será de todos o de ninguno. Sólo nos queda, aquí y ahora, que cada uno de nosotros trabaje sinceramente por el desarrollo de la racionalidad, por alzarnos sobre nuestra animalidad hacia lo más elevado en nosotros, por realizar la autonomía en el mundo, por humanizarnos, y así hacernos dignos del bien supremo.

\section{CONCLUSIONES}

El mundo es el espacio donde el ser humano debe labrarse su realización, el despliegue de la humanidad (moralidad, autonomía) en el mundo. Ahí se trazan los medios, las sendas posibles, pero también los peligros: el ser humano debe determinar él mismo su propio destino, y en ello acecha a cada momento el sello de su condena. El ser humano debe aclararse a sí mismo, y nada de transparente o soberano hay en ello, sino miedo, dudas, confusiones... así como valor. El ser humano es indigente, pero también resplandece en su dignidad.

Este recorrido es necesariamente común, social. El sujeto como individuo es como aquel espacio sin horizonte: un no-lugar, sin posibilidad de avanzar en ningún sentido. El individuo es aquello que encierra en su propio yo el mundo entero, de modo que no puede asegurarse la verdad, ni progresar ni mejorar, ni llegar al verdadero concepto del deber. El sujeto kantiano es su opuesto. En el horizonte de nuestra autonomía no encontramos sino a los otros. El horizonte de nuestra autonomía se abre ante un espacio intersubjetivo ético y político, único contexto para desarrollar la humanidad en mí. Pero los caminos hacia

35 KAnt, I., Antropología en sentido pragmático. Madrid, Alianza Editorial, 2010, 281. 
este horizonte deben ser construidos activamente por nosotros: no sólo debemos mantener el Estado y aproximarlo progresivamente hacia su ideal republicano, sino que debemos construir, pues aún está por construir el espacio cosmopolita donde elaborar entre todos públicamente, en igualdad y sin coacción, nuestro sentido común humano. La razón es esencialmente comunicativa. Debemos sin descanso trabajarla entre todos, en un espacio integrador de comunicación abierto a todo ser humano desde el que dar sentido al mundo. La razón humana misma, para poder manifestarse, necesita la relación con los otros.

CSIC. Instituto de Filosofía

Francisco Blanco Brotons

Franciscojose.blanco@cchs.csic.es

[Artículo aprobado para publicación en diciembre de 2016] 